\title{
0 cinema presta homenagem à poesia em Acidente, de Cao Guimarães e Pablo Lobato
}

\author{
Ana Gabriela Dickstein Roiffe \\ Universidade Federal Fluminense (UFF)
}

Resumo: Os cineastas Cao Guimarães e Pablo Lobato criaram o filme Acidente (2006) a partir de um processo de composição poética construído com o nome de 20 cidades do Estado de Minas Gerais. 0 artigo discute de que modo os procedimentos de realização desse longa-metragem, assim como seu resultado, costuram diferentes cruzamentos entre poesia e cinema. Em primeiro lugar, ainda que de forma indireta, o filme evoca tradições variadas na relação entre texto e cinematismo, incluindo produções das vanguardas que levaram a materialidade da palavra ao cinema, experiências de escrita inspiradas por Tristan Tzara e a relação da literatura com a questão espacial. Mais ainda, a maneira particular como a poesia inscreve-se em Acidente será também investigada por meio da revisão de conceitos como "filme textual", "cinepoesia", "dispositivo" e “cinema de poesia”.

Palavras-chave: Poesia, cinema, materialidade do texto, filme textual, Minas Gerais

Abstract: The film Accident (2006) was created by filmmakers Cao Guimarães and Pablo Lobato through a
process of poetic composition using the name of 20 cities in the state of Minas Gerais. The article discusses
how the procedures for making this feature film, as well as its result, build different relationships between
poetry and cinema. The film evokes varied traditions between text and cinematism, including avant-garde
productions that have brought the word's materiality to the cinema, writing experiences inspired by Tristan
Tzara, and the space issue in literature. Moreover, the particular way by which poetry is used in Accident will
N.- 41 - 12/ 2019 | 291-315 - ISSN 2183-2242 | http:/dx.doi.org/10.21747/21832242/litcomp41a13
INSTITUTO DE LITERATURA COMPARADA MARGARIDA LOSA | WWW.ILCML.COM
291
LITERATURACOMPARADA 
also be investigated through the revision of concepts such as "textual film", "cinepoetry", "dispositif" and "cinema of poetry".

Keywords: Poetry, cinema, text materiality, textual film, Minas Gerais

Cada uma das obras de Cao Guimarães é permeada pela natureza variada de suas atividades, num trânsito fecundo entre fotografia, vídeo e cinema. Trata-se de uma trajetória que opera por cruzamentos e estados de transitoriedade, propondo reflexões sobre o mundo, mas também sobre o próprio fazer da arte. Em seus filmes, desde o primeiro longa-metragem que dirigiu, O fim do sem fim (2001), até o mais recente, $O$ homem das multidões (2013), o artista tende a se movimentar por deslocamentos e percursos, seja em seus projetos documentais ou ficcionais, seja em seus trabalhos individuais ou nas inúmeras parcerias que formou. No entanto, as passagens que percorre não são fugidias, recuperando um olhar de atenção ao corriqueiro da vida a partir de enquadramentos fixos, de uma temporalidade prolongada e da exploração da tensão entre sons e silêncios. No curta-metragem Concerto para clorofila (2004), por exemplo, existe uma tentativa de conjugar a mínima vitalidade à máxima expressividade, assim como confirma a descrição da obra em seu site pessoal: "Conjunção de luz e sombra, formas, cores e texturas que denunciam a interrelação necessária de tudo que é vivo e vibra" (Guimarães 2004).

Algumas dessas características também se apresentam na trajetória de Pablo Lobato, a começar pelo reconhecimento da insuficiência de uma única via para explorar o seu processo criativo. É no encontro entre cinema, videoarte e artes plásticas que constrói seus mundos sensíveis, promovendo, como aponta Júlio Martins (2012: 159), um reencontro com as pequenas coisas e gestos do cotidiano. Essa captura de banalidades na sua presença mais imponente revela-se, por exemplo, nas fotografias, instalações e vídeos expostos em Da natureza das coisas (2016), no Museu de Arte do Rio, e especialmente nos filmes que dirigiu como integrante do coletivo mineiro Teia (2002-14), como Outono (2007) e Queda 
(2010). Na videoinstalação Bronze revirado (2011), o movimento dos personagens encarregados de fazer o sino de uma igreja soar valorizam-se pela edição e pela trilha, que dão relevo à harmonia e à intensidade rítmica produzidas pelos corpos em seus frágeis e calculados estados de equilíbrio. 0 ritual e o balanço retornam em Corda (2014), filmado durante o Círio de Nazaré, e Ventos de Valls (2013), que acompanha a volta de seis irmãos à sua cidade natal na Catalunha, entre fragmentos de conversas, sopros de ventania e uma inusitada festividade, em que se destaca uma gigantesca escultura humana formada pelos habitantes locais.

Do enlace entre esses dois universos surge o filme Acidente (2006), que ressalta não apenas o encontro com as cotidianidades, mas também a relação com a escrita, que já havia sido pontualmente sinalizada em trabalhos individuais dos dois artistas. Cao Guimarães, embora declare ser uma "pessoa da imagem" e defenda que o cinema deva distanciar-se da palavra teatral e literária, ${ }^{1}$ aproximou-se da literatura em determinados momentos da sua trajetória cinematográfica, como é o caso do filme Ex Isto (2010), uma livre transposição para as telas do romance-ideia Catatau (1975), de Paulo Leminski. Se neste caso o olhar sobre um romance já existente foi o ponto de partida para o seu trabalho, em outras obras o artista permitiu-se também brincar com a palavra, procurando conjugar o seu compromisso com a imagem a um processo de desvelamento da linguagem textual. Um exemplo é o curtametragem Word/World (2001), dirigido ao lado da artista Rivane Neuenschwander, em que formigas caminham por um chão de terra, carregando consigo recortes de papel com os termos "world" e "word". Já em um dos primeiros filmes de Pablo Lobato, Cerrar a porta (2000), a poesia surge inesperada, pela boca do próprio avô convalescente, fazendo irromper o encontro com a morte, o medo e a criação. Em Acidente, no entanto, a palavra assume outra dimensão: os artistas tornam-se eles mesmos poetas, criando e lapidando versos, fazendo da palavra a sua matéria-prima. É assim que demarcam discretamente a presença em uma esfera onde se encontram escrita e cinema, evocando procedimentos da literatura e atravessando mais uma fronteira nas duas trajetórias. 


\section{Uma ideia de escrita}

O filme Acidente surgiu de uma ideia de escrita, cujo mote inicial seria "compor poemas com nomes de cidades mineiras" (Afonso / Félix 2015). Isso levou os diretores Cao Guimarães e Pablo Lobato a selecionarem nomes que consideraram interessantes, em meio aos mais de 800 municípios do Estado de Minas Gerais e, após uma primeira triagem, a desenvolverem um processo de composição de diferentes poemas. Restou como resultado desse exercício aquele que lhes parecia mais instigante, cuja formação incluía o nome de 20 cidades mineiras: Abre Campo, Águas Vermelhas, Caldas, Descoberto, Dores de Campos, Entre Folhas, Espera Feliz, Ferros, Fervedouro, Heliodora, Jacinto, Olhos D'Água, Pai Pedro, Palma, Passos, Planura, Tiros, Tombos, Vazante e Virgem da Lapa. A partir dessa escolha, uma primeira intenção consistia em investigar a origem dos nomes dessas cidades, para então percorrê-las, dando prosseguimento a uma espécie de investigação. 0 projeto, no entanto, tomou uma diferente dimensão quando os diretores decidiram visitar as cidades sem que fosse realizada qualquer pesquisa prévia a respeito de personagens, tramas ou mesmo das informações locais mais elementares. Tudo seria fruto de uma atitude de observação e espera, a partir de um poema como norte, que funcionaria como uma espécie de poemarroteiro. 0 resultado dessa jornada é um filme constituído por pedaços de narrativas e fragmentos visuais, nos quais os diretores exercitam a potência de objetos, fachadas, luzes, sons, falas.

O poema que guia o percurso é um elemento essencial de condução do filme. Na obra de 72 minutos, a primeira imagem que surge é a de uma tela preta, sobre a qual aparecem e desaparecem mapas de variadas cidades, seguidos do texto "20 cidades / MG, Brasil”. A partir de então, o filme acompanha o seguinte encadeamento: cada cidade é apresentada a partir de um mapa e seu nome por escrito sobre tela preta; logo depois, aparecem as sequências de imagens relativas àquela localidade; e tudo continua na cidade seguinte. Aos poucos, descobre-se que a ordem das cidades no filme segue a mesma do poema composto pelos diretores. Isso porque, em três diferentes momentos, o ritmo se interrompe, e a tela se preenche de estrofes sequenciais do poema. A primeira ocorrência se dá depois de o filme percorrer as cidades Heliodora, Virgem da Lapa, Espera Feliz, Jacinto e Olhos d'Água. 
Aos 16 minutos e meio de filme, surge, sobre uma tela escura, com um difuso ponto de luz, a primeira estrofe do poema:

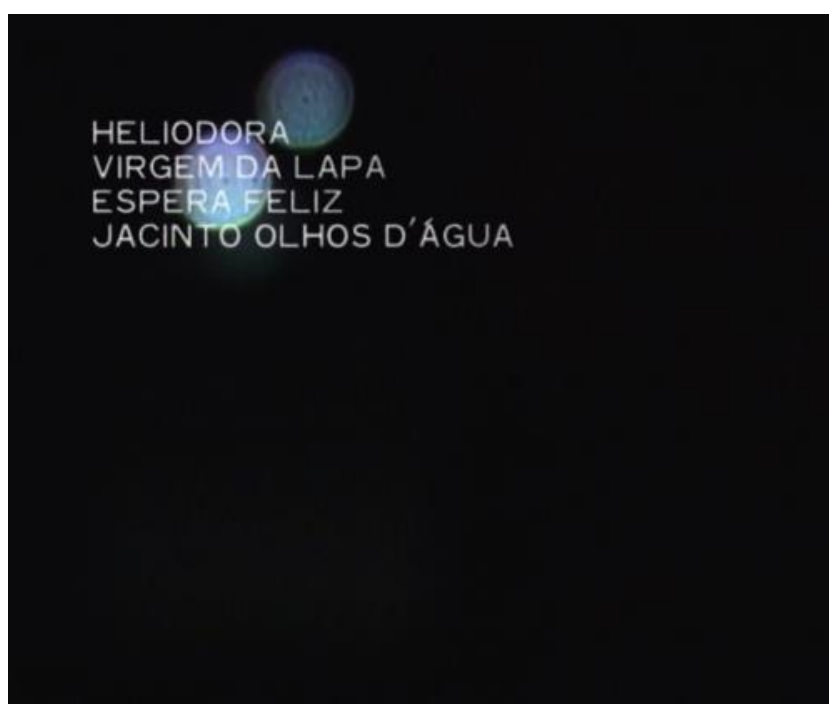

Depois de desaparecer da tela, a mesma estrofe se repete, mas desta vez traduzida para o inglês ${ }^{2}$ :

\section{HELIODORA}

VIRGINOF THE ROCK

JOYFUL AWAITING

HYACINTH WATERY EYES

Aos 39 minutos e meio, sobre a imagem de um céu alaranjado, entre nuvens e uma fresta do sol, lê-se a segunda estrofe do poema: 

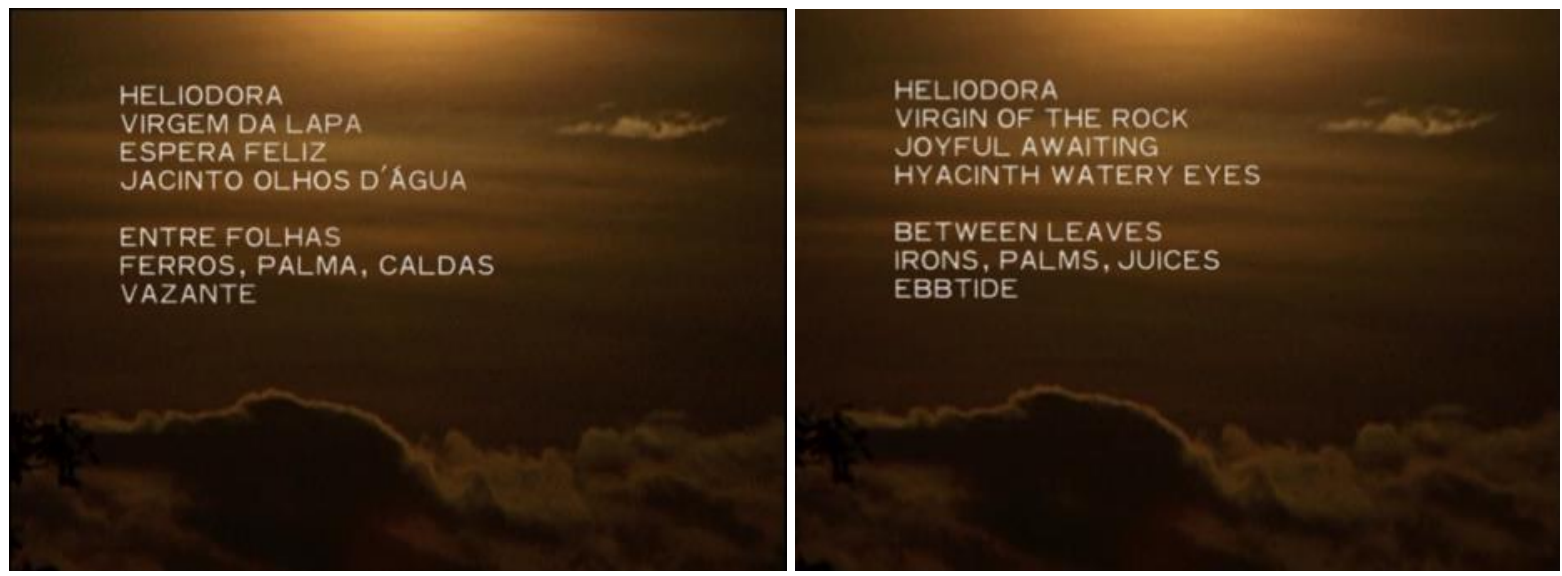

E finalmente, aos 68 minutos, sobre uma imagem pouco nítida de um campo de trigo, forma-se na tela o poema integral:
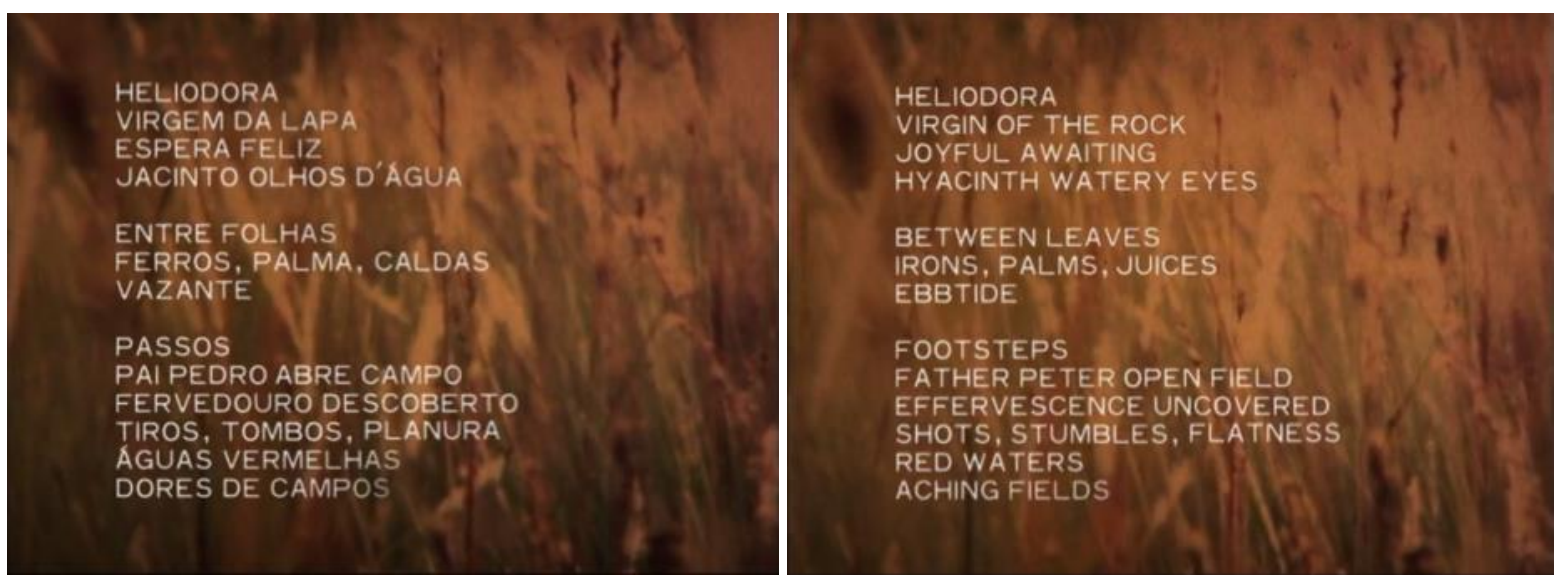

Desenha-se, assim, uma trajetória que se desenrola por entre sons, imagens e textos em movimento. Seu traçado resiste a sínteses, costurando momentos de apreensão dificultosa, tamanha a variedade de linhas de fuga. Ainda assim, é possível vislumbrar, como figurantes silenciosos, exemplares de tradições literárias e cinematográficas que dialogam com Acidente, capturando o filme como mais um representante de debates há muito mapeados. 


\section{Um filme textual}

Em primeiro lugar, ao fazer do texto imagem na tela cinematográfica, os diretores de Acidente acabam somando-se ao conjunto de filmes que trabalham com a materialidade da palavra nas suas mais variadas formas. É interessante notar que a exibição de palavras e textos nas telas do cinema é tão remota quanto a própria história do cinema. Até o surgimento do cinema sonoro, intertítulos colaboravam para encadear as narrativas, e os textos também apareciam em cartelas de abertura e nos créditos dos filmes. Especialmente nas décadas de 1910 e 1920, os intertítulos se tornaram um elemento corrente nas produções cinematográficas, indicando dados temporais e espaciais, em uma antecipação das situações que logo seriam apresentadas. ${ }^{3}$ Em Intolerância (1915), de D.W. Griffith, por exemplo, o seguinte texto introduz a narrativa: "The girl of our story keeps house for her father who works in a Jenkin mill. With a wage of $\$ 2.75$ a day, a little garden, four hens, dito geese, and a fair measure of happiness and contentment". ${ }^{4}$ Nos anos seguintes, os textos se encurtaram, sofisticaram-se e passaram a ser usados também para apresentar os diálogos dos personagens, que, por esse motivo, ganharam contornos cada vez mais complexos. Foi assim que parte da história do cinema associou a função dos intertítulos ao que, anos mais tarde, no cinema sonoro, ficou conhecido como voz over.

Alguns filmes, no entanto, começaram a demonstrar que o uso da palavra escrita no cinema poderia originar exercícios mais inventivos. Manhatta (1921), de Charles Sheeler e Paul Strand, tornou-se um marco nesse sentido, por apresentar um texto que ultrapassava a função de desenvolver a narrativa. Tratava-se de um curta-metragem de dez minutos com imagens que apresentam pedaços da vida urbana de Nova York, como seus arranha-céus e operários durante o expediente. Em meio a essas imagens, surgiam cartelas em que os edifícios de Manhattan figuravam como panos de fundo de trechos do poema "Mannahatta", de Walt Withman. 


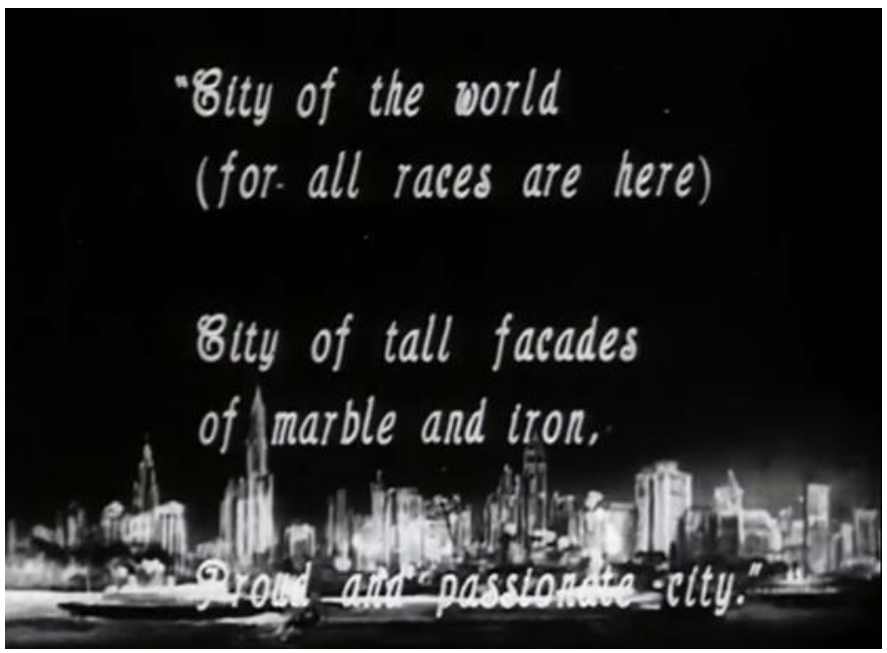

Imagem do filme Manhatta (1921), de Charles Sheeler e Paul Strand

Vê-se, assim, que Manhatta já não procura finalidades narrativas na montagem. Existem textos-imagens que, no máximo, ilustram, problematizam ou complementam a imagem em movimento, mantendo uma independência entre os diferentes fragmentos que compõem o filme.

A radicalização da escrita no cinema seria explorada pelas vanguardas do início do século XX, que destacaram a materialidade do texto em tela, transformando-o em imagem. Um exemplo é Ballet Mécanique (1924), de Dudley Murphy e Fernand Léger, em que, em meio à sinfonia de imagens, brinca-se com a seguinte frase e seus fragmentos: "On a volé un collier de perles de 5 million". 5 Outro caso é o filme Anemic Cinema (1926), em que Marcel Duchamp explorou a escrita a partir de discos óticos que giravam com diferentes textos. As frases não mostravam qualquer nexo aparente, mas produziam aliterações, jogos de palavras e outras provocações, tais como "Si je te donne un sou, me donneras-tu une paire de ciseaux?" ou "Esquivons les ecchymoses des Esquimaux aux mots exquis".6 Há ainda nessas décadas exemplos esparsos que substituíram a lógica narrativa pela relevância iconográfica do texto, aproveitando a tela como um espaço gráfico. Naquele momento, é como se a palavra escrita houvesse sido tomada como apenas um dentre os diversos elementos das coreografias modernas maquínicas que se insurgiam no seio da sociedade industrial. 


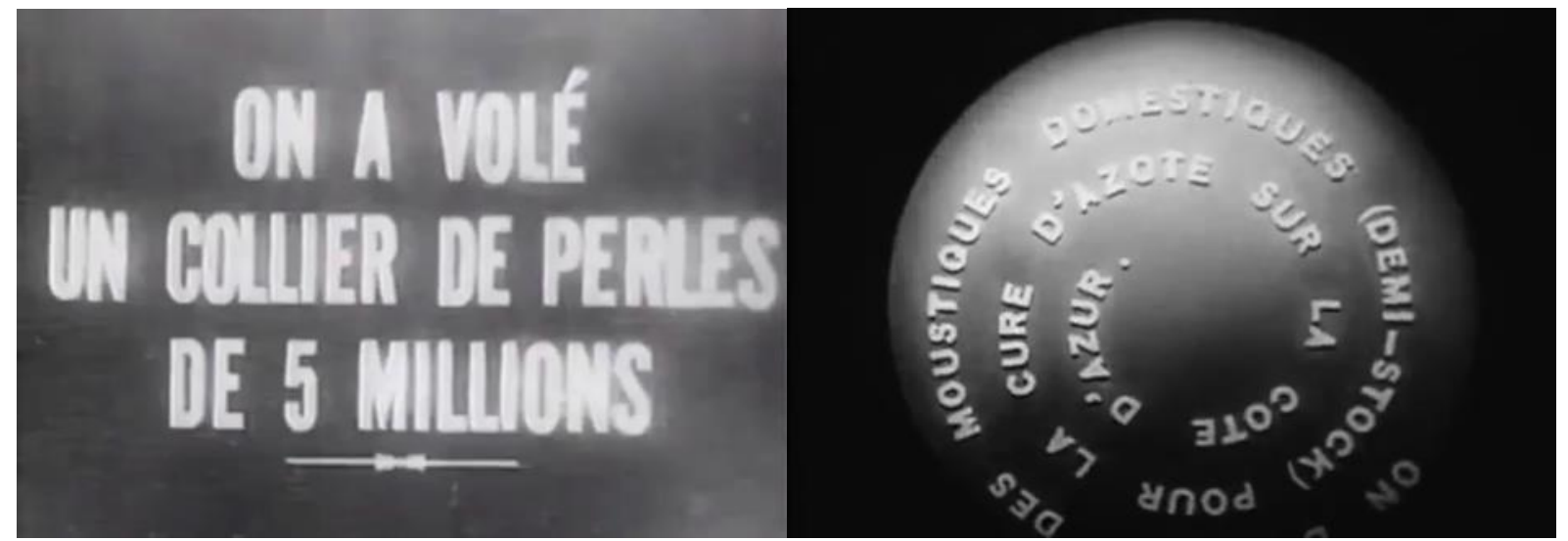

Imagens dos filmes Ballet Mécanique (1924), de Dudley Murphy e Fernand Léger (à esq.), e Anemic Cinema (1926), de Marcel Duchamp

Justin Remes (2015) aponta o filme de Duchamp como um divisor de águas no uso do texto no cinema para fins que não fossem narrativos ou paratextuais. Esse tipo de produção colocaria em pé de igualdade o uso de palavras escritas e imagens no cinema, destacando letras, palavras, números, sinais de pontuação e outras formas de texto manuscrito ou tipográfico. "No mundo pós-duchampiano, a palavra escrita poderia ser tão central para um filme quanto uma imagem. A porta foi aberta para um novo tipo de cinema: o filme textual."7 (Remes 2015: 70-1).

O filme So Is This (1982), de Michael Snow, seria um dos mais representativos exemplos do filme textual, levando ao paroxismo o tensionamento entre texto e imagem na tela cinematográfica. Trata-se de um filme mudo, construído apenas com a exibição de palavras na tela, uma a uma, sobre um fundo preto. A partir de diferentes ritmos e qualidades de imagem, a junção de palavras forma frases que estimulam uma reflexão sobre a atividade do próprio espectador. Mais ainda, o filme convoca a uma experiência de leitura diferente daquela proposta pelo livro, tal como a substituição da atividade solitária da leitura de um livro pela leitura coletiva da sala de cinema, o que é sinalizado pelo próprio texto exibido: "But look at the bright side of it: Sharing! When was the last time you and your neighbour read together? This is communal reading, it's Group Lit! We could even read aloud but let's not". ${ }^{8}$ Remes (2015: 73) destaca também que, à diferença de uma experiência 
de leitura em um livro convencional, So Is This recupera a importância das palavras, na medida em que exibe cada uma delas individualmente. Outros fatores importantes seriam ainda a relação com a temporalidade e a falta de controle do espectador sobre o ritmo da própria leitura. ${ }^{9}$
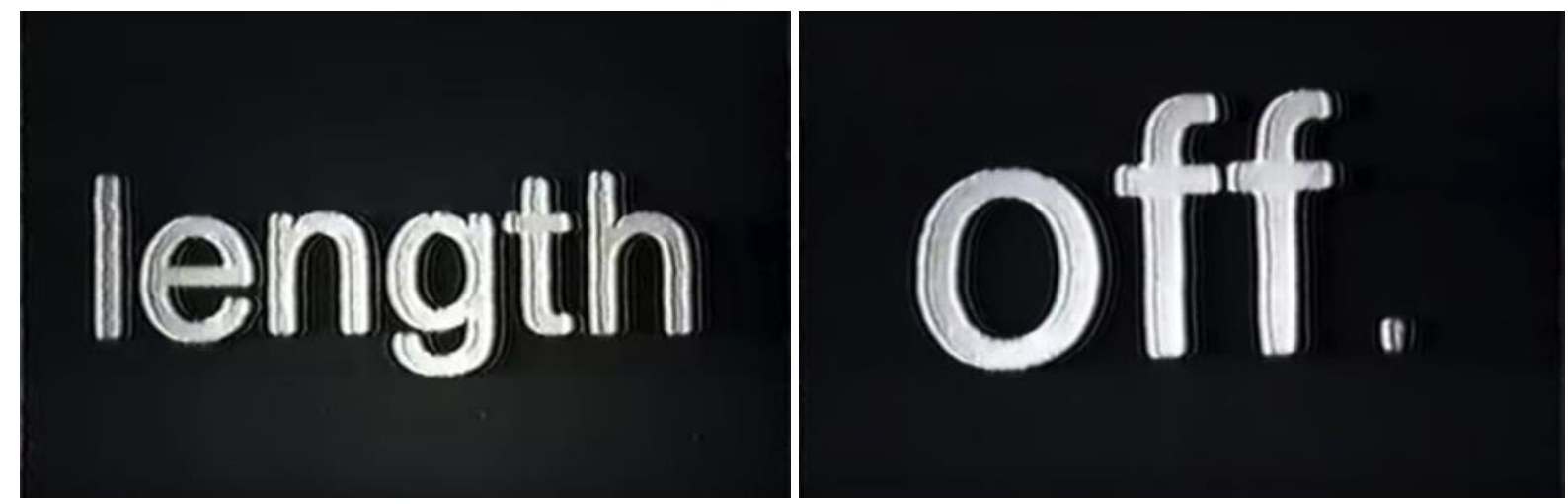

Imagens do filme So Is This (1982), de Michael Snow

Acidente se inscreve nessa história, mas construindo uma relação própria entre texto e imagem. A escrita está na cartela de apresentação de cada cidade - o que poderia, a grosso modo, acenar para os intertítulos do cinema mudo, responsáveis por introduzir as ações do filme -, mas especialmente no poema composto pelos diretores. Como um filme contemporâneo e consciente das referências que lhe antecedem, não procura problematizar a relação entre texto e imagem no cinema, a exemplo dos vanguardistas e do conceitualismo de artistas como Michael Snow; em Acidente, o texto amplia a relação funcional com as imagens, criando fissuras e atuando como um corpo estranho, que pergunta algo que não se sabe bem o que é e responde com novas provocações. Sua presença acende faíscas que remetem à própria particularidade da poesia na sua relação com o cinema. Como questionava o cineasta Eduardo Valente (2006), Acidente deixa em aberto: seria um "filme baseado em um poema, ou poema baseado em um filme"? 


\section{Pegue uma tesoura}

Como um filme textual, o longa-metragem de Cao Guimarães e Pablo Lobato também evoca indiretamente toda a linhagem literária iniciada por Stéphane Mallarmé, que deflagrou impurezas da linguagem e outorgou cinetismo às palavras, cooptando elementos do cinema para dentro das práticas de escrita. Chamada por Christophe Wall-Romana (2013) de cinepoesia, essa tradição nomeia o trabalho de poetas e escritores em diferentes períodos, programas estéticos e escolas, abarcando desde a adoção do cinema na criação de novos gêneros e práticas textuais até a maneira como a reflexão sobre a indústria cinematográfica atualizou a poesia.

Acidente dificilmente poderia ser alocado em meio ao conjunto de obras que, derivadas de Mallarmé, trabalham o caráter gráfico do texto, valorizando sua representação sonora, explorando as relações na página entre vazios e preenchimentos e revirando a semântica dos versos, a exemplo de trabalhos de escritores tão diversos quanto Guillaume Apollinaire, Ezra Pound, e.e. cummings, James Joyce, John Cage ${ }^{10}$ e os irmãos Campos. Isso porque seu texto se imprime em tela a partir de movimentos suaves e numa disposição mais convencional da poesia, que não demonstra uma relação formal com exercícios tipográficos e conceituais. Por outro lado, é flagrante que o procedimento de composição poética dos diretores-escritores Cao Guimarães e Pablo Lobato se aproxima de outro dos

discípulos de Mallarmé, Tristan Tzara. Foi ele quem se posicionou criticamente frente à expressividade romântica e simbolista na poesia a partir de uma atividade de recorta-ecola, cuja principal referência é a "Receita para fazer um poema dadá":

Pegue um jornal.

Pegue uma tesoura.

Escolha no jornal um artigo com o comprimento

que você pretende dar ao seu poema.

Recorte o artigo.

Depois, recorte cada uma das palavras que formam

este artigo e coloque-as em um saco.

Agite suavemente.

Em seguida, retire cada recorte um por um. 
Copie conscientemente na ordem em que eles saíram da bolsa.

0 poema se parecerá contigo.

E eis um escritor original

e uma sensibilidade encantadora. ${ }^{11}$

A aparente simplicidade do exercício de Tzara mascara a importância de seu legado para a construção poética que se seguiu desde então. Os cut-ups de William Burroughs e Brion Gysin, por exemplo, foram fruto direto da poesia Dadá, trazendo um exercício semelhante, porém ampliado com relação ao de Tzara. Tratava-se de uma combinação aleatória de trechos de material escrito, mas a partir de fontes diferentes, tais como material de imprensa e a Bíblia. Essa espécie de fagocitose, adotada na criação de livros como The Soft Machine (1961), The Ticket that Exploded (1962) e Nova Express (1964) ${ }^{12}$, desdobrou-se também pela obra de escritores contemporâneos da chamada "escrita não criativa", de Kenneth Goldsmith, e da poesia generativa, cuja base são em geral bancos de dados e outras fontes digitais. Mais ainda, tornou-se ilustração frequente de abordagens ancoradas em questões intertextuais e intermediais.

O poema Dadá de Tzara ressoa na criação poética de Acidente, configurando um ponto de partida semelhante: ambos surgem de procedimentos construídos com a intenção de provocar o acaso, procurando criar condições de ampliar as possibilidades de uma escrita plenamente consciente de si.

Enquanto na literatura se renovam periodicamente os projetos de acaso em diferentes vertentes, o cinema tem usado esse tipo de estratégia com maior frequência nos últimos anos, numa tendência que tende a se reunir sob o conceito de "dispositivo". Diferentes autores relacionam as produções cinematográficas contemporâneas ao uso do dispositivo, mas nem sempre com a mesma intenção. Para André Parente (2007), o cinema do dispositivo seria um contraponto ao cinema representativo-institucional, propondo-se a ativar diferentes relações com o espectador, a partir principalmente das novas tecnologias e da arte contemporânea. Em sua análise sobre o conceito, remete tanto aos teóricos estruturalistas que o conceituaram nos anos 1970, como Jean-Louis Baudry, Christian Metz e Thierry Kuntzel, como aos filósofos Michel Foucault, Gilles Deleuze e Jean-François 
Lyotard, que fornecem as bases mais importantes dentro de sua definição, sintetizada da seguinte forma: "o dispositivo remete a um conjunto heterogêneo de elementos que podem, em certos momentos, se cristalizar em uma formação ou 'episteme' dominante” (Parente 2007: 15). Já em Cezar Migliorin (2005), o dispositivo no cinema não se refere a obras instalativas, mas a estratégias narrativas capazes de produzir acontecimento na imagem e no mundo. Nesse sentido, o dispositivo introduz linhas de ativação em um universo escolhido, pressupondo dois movimentos complementares: o extremo controle e a absoluta abertura. $^{13}$

É interessante observar que a construção de dispositivos tem atravessado diferentes produções do cinema contemporâneo. O documentário O fim e o príncípio (2005), de Eduardo Coutinho, por exemplo, apresenta uma notável semelhança com Acidente em termos de dispositivo (e não de resultado), na medida em que o documentarista também filmou em uma cidade desconhecida (no caso de Coutinho, a seleção foi feita na Paraíba) e sem qualquer pesquisa de personagens ou locações. ${ }^{14}$

A própria obra de Cao Guimarães, mais além do filme Acidente, tem sido associada ao conceito de "dispositivo" por diferentes autores (Almeida 2016, Lins 2007, Migliorin 2005). Embora seja possível associar características de ambas as definições na sua trajetória, a segunda delas - que trata menos do aspecto filosófico do dispositivo e mais de um procedimento que se assemelha ao jogo - parece conformar com mais propriedade as suas intenções. Em Rua de Mão Dupla (2004), por exemplo, o artista criou um estratagema segundo o qual desconhecidos deveriam trocar de casa entre durante 24 horas, registrando com câmeras digitais imagens da casa alheia e, com isso, mergulhando num exercício de imaginação a respeito do morador daquele espaço. Em outro projeto que resultou em um livro, Histórias do não-ver (2001), Cao Guimarães criou uma experiência em que ele próprio seria vedado, sequestrado e levado a diferentes cidades e países por alguns de seus amigos. Já em Pablo Lobato, um "dispositivo de produção do esquecimento" (Brasil apud Martins 2012: 159) é acionado em Expiração, instalação produzida a partir de 2008, em que parte do material audiovisual bruto do artista passa pelo duplo processo de memória e 
apagamento, quando se deixa orientar por um software, que comanda os minutos ou dias de exibição das imagens, antes de serem definitivamente destruídas.

A construção de um mecanismo disparador de ações retorna em Acidente. Neste caso, no entanto, o artifício para cumprir objetivos é fundado na palavra. Por esse motivo, Consuelo Lins (2007: 123) define o procedimento do filme como um "dispositivo-poema", em que os diretores constroem uma máquina de produzir imagem que exerce poder sobre eles mesmo, determinando regras e diminuindo o que chama de "excesso de intencionalidade". De forma análoga, não seria a própria “Receita para um poema Dadá" um dispositivo-poema?

\section{Poesia e mundo}

De nada valeriam a palavra e o dispositivo de Acidente não fossem a sua matéria as próprias coisas do mundo. É nesse sentido que o filme alude a mais um sentido de poesia, aquele cunhado na célebre conferência apresentada no Festival de Pesaro em 1965 por Pier Paolo Pasolini: o "cinema de poesia". Influenciado pela força então hegemônica da semiótica na academia, o cineasta procurou desvendar a comunicação cinematográfica, costurando uma associação terminológica com a literatura. Se historicamente a tradição cinematográfica parecia trabalhar por meio de uma língua de prosa, com destaque para a prosa narrativa, Pasolini questionava de que modo seria possível traduzir a linguagem da poesia para o cinema. Não se tratava, no entanto, de "filmar poesia" ou entender o cinema como poético, mas de descobrir a poesia: “0 cinema é um meio para descobrir a poesia, seja a poesia de um poeta ou a poesia do mundo"15 (Pasolini 1970: 51). Diferentemente do que ocorreria com as linguagens literárias, cuja base seriam as palavras (chamadas por ele de lin-signos), as linguagens as cinematográficas, ancoradas nas imagens (im-signos), teriam como fonte a própria realidade. Para Pasolini, os signos do cinema seriam, assim, a própria vida. ${ }^{16}$

Acidente dialoga com essa poética da vida desenvolvida pelo cinema por meio de um certo olhar e da formação de um estilo. Ainda assim, é importante retornar ao ponto de que seu cinema de poesia se funda sob o registro da escrita textual. Nesse sentido, é a partir da 
poesia do texto que o filme permite-se capturar a poesia do mundo e revelá-la ao público a partir de um processo de edição. De alguma maneira, os diretores rumam a um "fazer poesia" mais semelhante à ampla definição de Jean-Luc Nancy (2004). Para o filósofo, a poesia é um conjunto de qualidades que não estão reservadas ao tipo de composição denominado poesia. É por esse motivo que, segundo Nancy, “A poesia é, por essência, mais e outra coisa que a própria poesia. Ou ainda: a própria poesia pode muito bem ser encontrada ali onde sequer há poesia. Ela pode até mesmo ser o contrário ou a recusa da poesia, e de toda a poesia" (Nancy 2004: 416-7, grifo do autor). A poesia, portanto, é um "sentido por fazer", é "fazer tudo falar". Consonante com o que diriam os próprios diretores de Acidente, o projeto do filme era ouvir o que as cidades tinham a dizer.

Tome-se como exemplo a primeira localidade apresentada no filme, Heliodora. A cidade surge para o espectador numa noite chuvosa, ao som de trovões, luzes que piscam, carros e sombras de árvores. Na frente de uma fachada com a palavra "Convívio", uma pessoa espera. Mais adiante, um homem iluminado por uma única vela e ao som de um sino da igreja local olha para a câmera e discorre sobre uma música de que gosta e sobre as músicas que o ajudam a esquecer a falta de amor em sua vida. Durante uma breve caminhada, conversa sobre a própria homossexualidade, sexo, amor e confiança, até chegar ao que parece ser a sua própria casa. "Estou cansado de ser humilhado", desabafa frente à câmera. Ali estão uma menina e um senhor, que dorme. Apaga-se a luz.
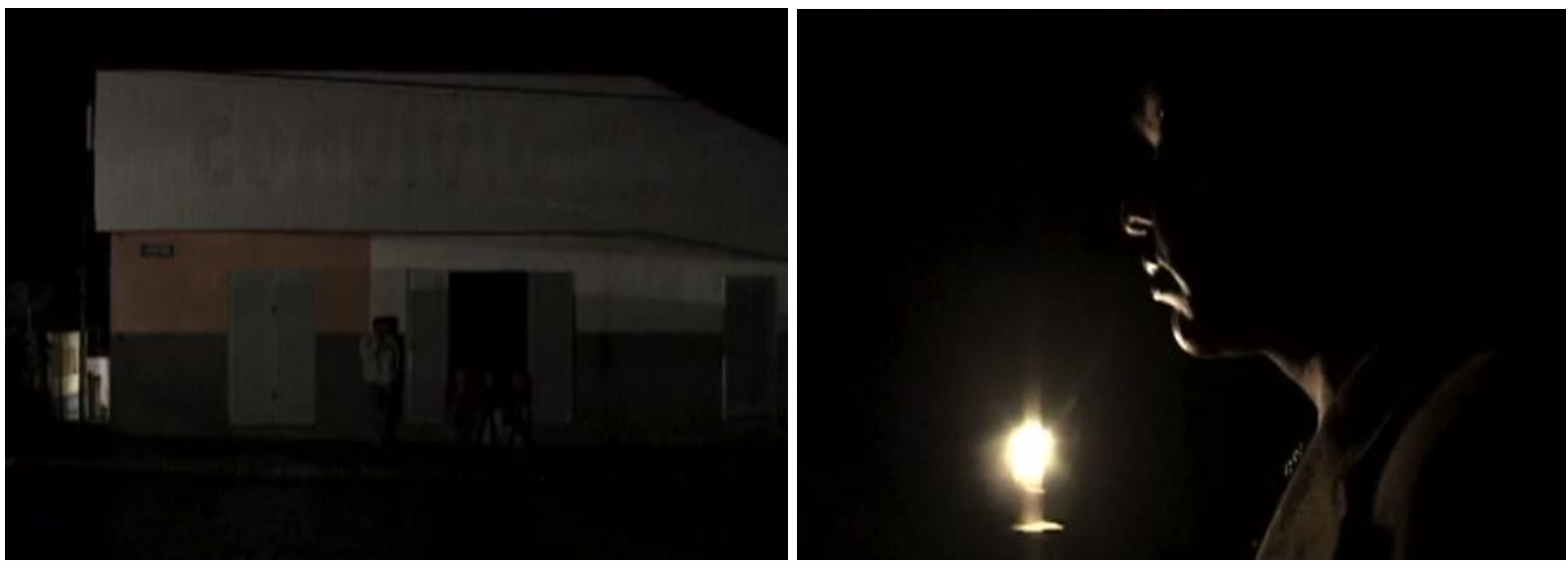

Imagens da cidade Heliodora, no filme Acidente (2006), de Cao Guimarães e Pablo Lobato 
Essa primeira entrada no filme anuncia que as palavras não estão ali apenas casualmente, mas também estimulam o nosso próprio desejo narrativo, inundando as possibilidades do pensamento. E se Heliodora fosse o codinome do personagem que conhecemos na cidade? Ou alguém importante na sua história? E o que dizer do "convívio" diante de um discurso que alega a impossibilidade da convivência? Portanto, o filme trabalha sempre a partir de uma sofisticada conversa com o espectador, em que as imagens não se entregam facilmente para deglutição e, ao mesmo tempo, as palavras delimitam certas virtualidades. Em Virgem da Lapa, por exemplo, uma procissão com crianças e idosos percorre as ruas da cidade, evocando o aspecto religioso que dá nome ao povoado. Na cidade de Jacinto, o filme mostra uma fotopintura antiga de um casal na parede e um senhor cantando, que poderia ser o próprio Jacinto. Em Olhos D’Água, um senhor de chapéu verde no bar olha para a câmera. Teria ele olhos d'água ou seria a palavra um despertar para os olhos do personagem?
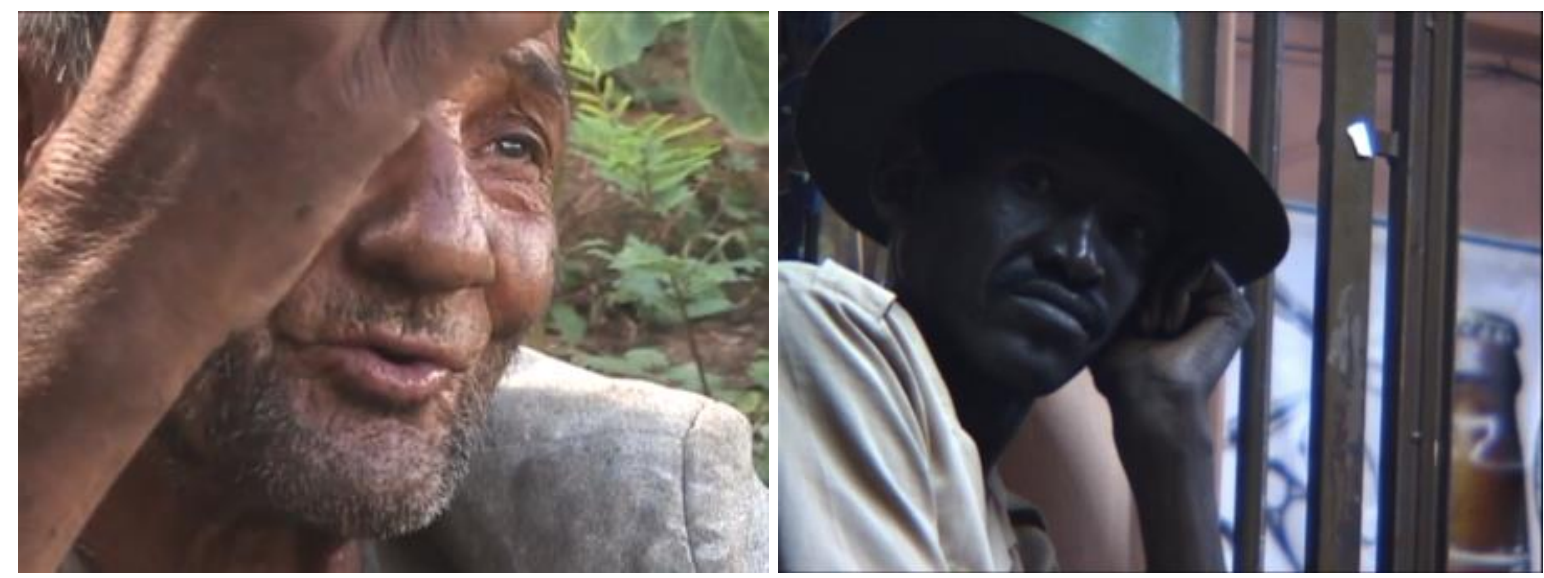

Imagens das cidades de Jacinto (à esq.) e Olhos d'Água (à dir.), no filme Acidente (2006)

Essa relação de estímulo se torna ainda mais nítida em locais como Espera Feliz, em que diferentes sequências mostram objetos estáticos que parecem "esperar” por uma resolução. Seguem alguns exemplos:

1- Vê-se uma fotografia de um time de futebol torta na parede; logo depois, surge um homem que ajeita o quadro, deixando-o perfeitamente equilibrado. 

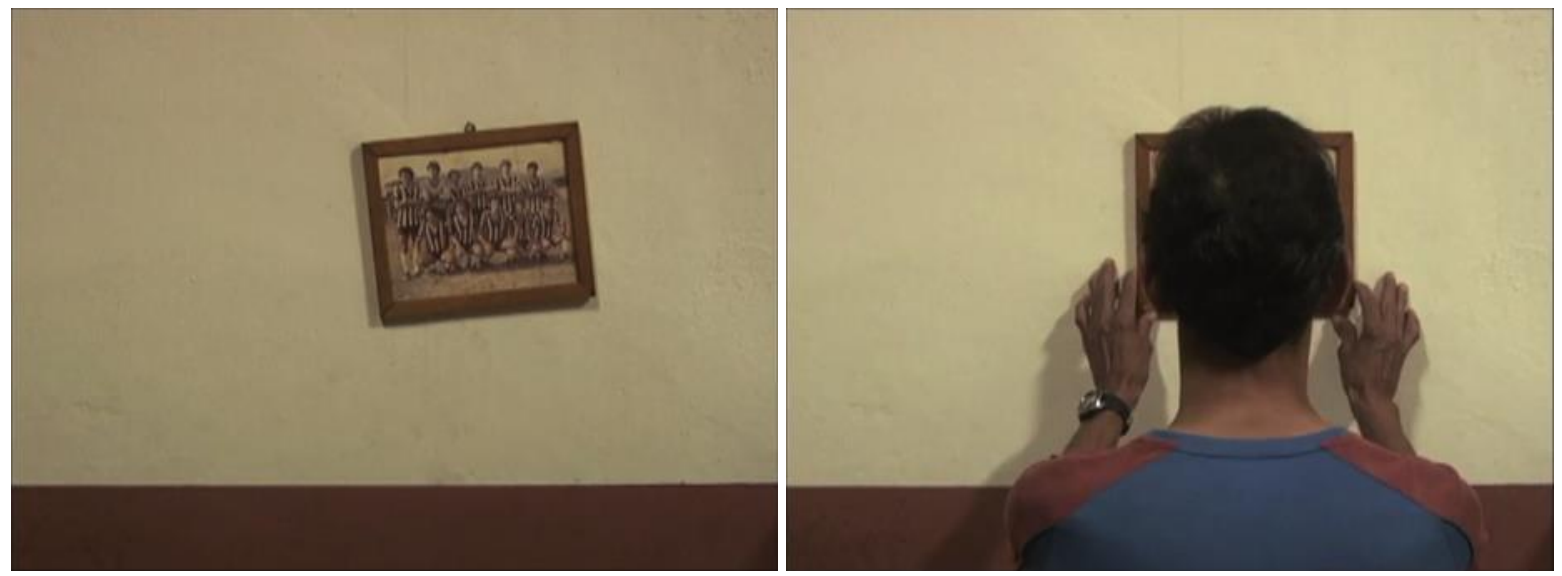

2- Uma roda de bicicleta está em primeiro plano e, logo, uma mão surge para atarraxar a sua câmara de ar.
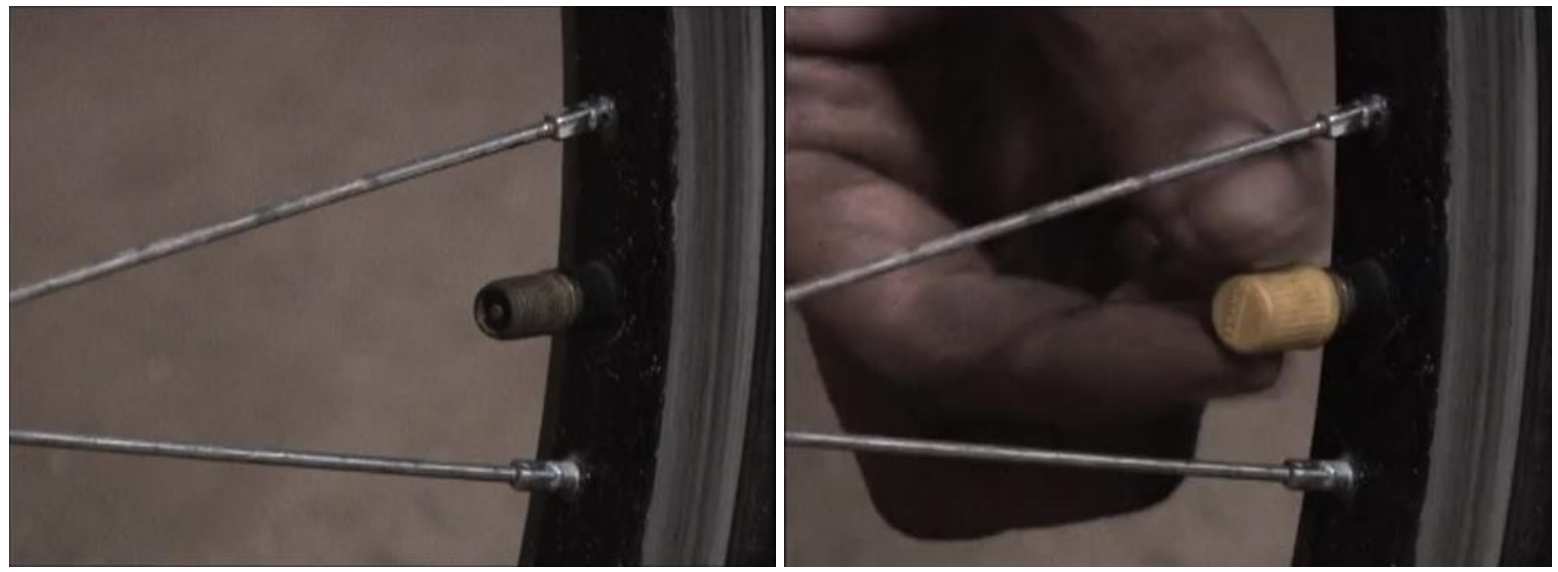

3- Dois copos de plástico se encontram no chão e, em seguida, movimentam-se numa espécie de dança.
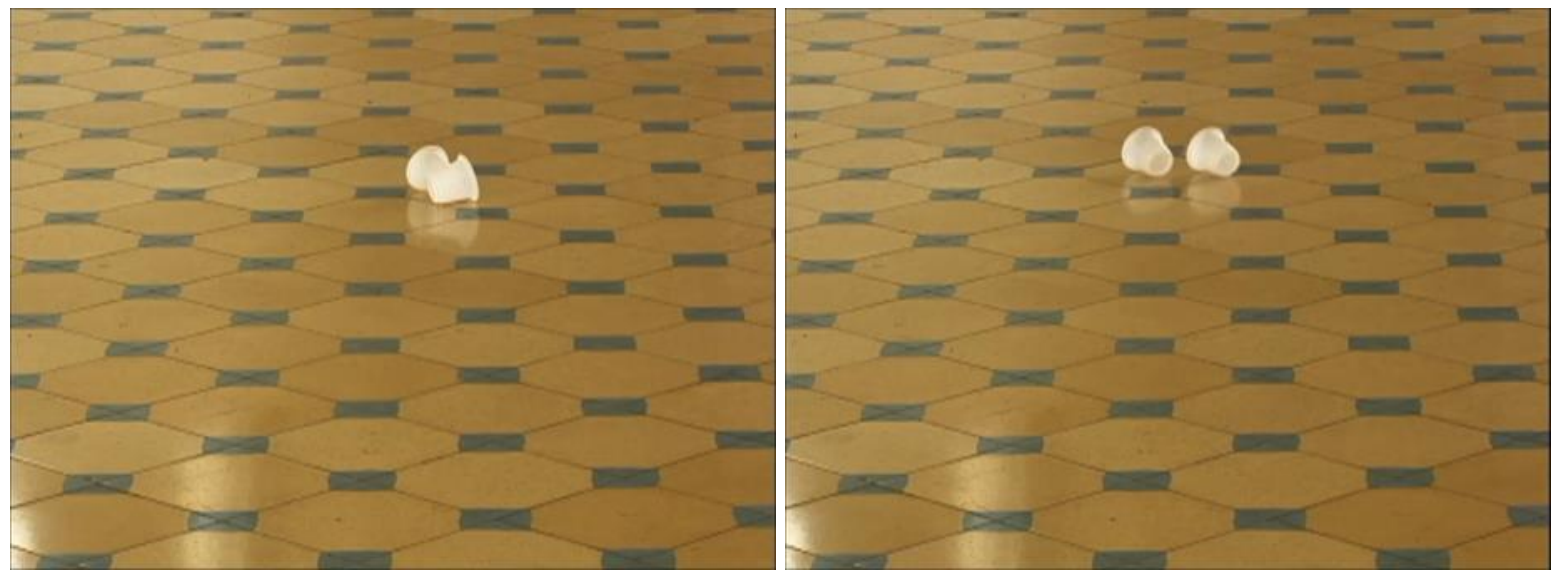
Tudo leva a crer que, se a importância do acaso como norteador das filmagens se reitera no discurso dos diretores, a montagem não adota a casualidade como guia, construindo criticamente as concordâncias e dissonâncias que se apresentam na tela. É interessante notar que os cineastas assinam o filme também como editores das imagens e, portanto, são responsáveis por fazer as palavras operarem como disparadoras da ação. Com isso, num primeiro momento, seria possível reconhecer nos diretores o papel de geradores de palavras instrumentais, utilitárias, comunicativas, assumindo o papel de escreventes. ${ }^{17}$ No entanto, nessas palavras o efeito de incitar ações se soma ao caráter estético da criação poética, que se realiza tanto na escrita como na própria imagem. 0 poema de Acidente não produz reações, mas amplia sentidos, em sua coreografia de palavras, versos, imagens e sons. Nisso se reconhece também que a textualidade ultrapassa o sentido de roteiro-poema, costurando um novo pacto com o espectador, transformado também em um leitor, na expectativa de prever os versos seguintes, de profetizar a forma do poema.

\section{Poesia com sotaque}

Os jogos coreográficos entre as cenas do filme desenham, assim, uma dialética em que o desejo de entrega ao aleatório é constantemente demarcado por intencionalidades, que oferecem contornos, limites e pedaços de tramas. Nesse sentido, Acidente apresenta um fio condutor definido, que alimenta a poesia, incita a ação e provoca a reflexão. Trata-se de Minas Gerais, o elo ancestral entre Cao Guimarães e Pablo Lobato, nascidos respectivamente nas cidades de Belo Horizonte e Bom Despacho. Ao optar por percorrer localidades desconhecidas desse grande estado constituído por cidades interioranas, os artistas atualizam memórias afetivas para construir possíveis futuros. Por esse motivo, Acidente carrega consigo um forte sotaque mineiro, que se reconhece não apenas no convite a adentrar portas abertas que parecem emanar cheiro de café, mas pelas imagens que a obra poética dos escritores locais exalam em cada captura de delicada aspereza. Como acidentes, surgem sopros de Carlos Drummond de Andrade, que aporta um pouco de Itabira a cada cidade mineira, de Conceição Evaristo, que curiosamente tem um de seus livros chamado de Olhos D’Água (2014) - homônimo de uma das cidades retratadas no filme -, ou 
até de Bárbara Heliodora, conhecida como a primeira poetisa brasileira e que nomeia (casualmente?) a primeira localidade do filme.

Dez anos depois do lançamento de Acidente, Pablo Lobato (2016) comentou o quanto cada vez mais se deixava permear por um estado de evocar, que se dispunha entre a não-busca e o encontro. Se o filme evoca o pequeno gesto, também parece evocar a própria poesia, prestando uma homenagem a diferentes versões de sua relação com o cinema. Em torno de uma poesia que surge intensa e presente, embora como efeito incalculado, reúnem-se, portanto, manifestações que fazem a materialidade da palavra interrogar a narrativa, vertentes que constroem dispositivos-disparadores para a criação textual, o gosto mineiro que transpira nas palavras de poetas de todos os tempos e, sobretudo, qualquer desvelamento das centelhas poéticas dentro ou fora da poesia. É assim que, meio sem querer, Acidente reverencia a poesia de forma plural, aguardando à espreita a evocação daquilo que ainda está por vir.

\section{NOTAS}

${ }^{1}$ Em entrevista, o artista criticou o aspecto dramático do cinema:

O cinema tem uma forte impregnação do teatro, da literatura, desde o seu início. É uma arte que ainda está engatinhando, ainda está de fralda. No início do cinema, quem foram os produtores cinematográficos? Gente da literatura e do teatro, basicamente, que impregnou demais a arte cinematográfica com a palavra e o aspecto dramático. Durante a história do cinema, houve várias tentativas de buscar outra essência. Algo mais elementar, imagem e som, audiovisual. Com a palavra sendo uma das possibilidades sonoras, não a principal. 0 cinema é muito impregnado o tempo inteiro pela palavra e pela atuação do teatro. (Cohn et alii 2010: 141) 
2 É interessante notar como a tradução assumiu a relação semântica formada pelas cidades no poema.

${ }^{3}$ Embora a discussão não seja recente, vale lembrar que os intertítulos foram alvo direto dos defensores do "cinema puro" na França, que apostavam no desenvolvimento do cinema como arte autônoma e independente de qualquer influência escrita.

${ }^{4}$ Em português, "A garota da nossa história mantém a casa para o pai, que trabalha num moinho de Jenkin. Com um salário de US\$ 2,75 por dia, um pequeno jardim, quatro galinhas, gansos e uma boa medida de felicidade e contentamento". Tradução minha.

${ }^{5}$ Em português, "Nós roubamos um colar de pérolas de cinco milhões". Tradução minha. Filme Disponível em <https://www.youtube.com/watch?v=yrfibt6Bkwc> (último acesso em 25/06/2019).

${ }^{6}$ Minhas traduções aproximadas seriam "Se eu te der um centavo, você vai me dar uma tesoura?" e "Esquive as equimoses dos esquimós com palavras gostosas".

${ }^{7}$ No original, "In the post-Duchampian world, the written word could be just as central to a film as imagery. The door had been opened for a new kind of cinema: the textual film". Tradução minha, grifo do autor.

8 Em português: "Mas olhe para o lado bom disso: compartilhar! Quando foi a última vez que você e seu vizinho leram juntos? Isto é leitura comunitária, é literatura em grupo! Nós poderíamos até ler em voz alta, mas vamos não fazer isso". Tradução minha.

9 Remes (2015: 75) ressalta que muitas dessas experiências se transformaram nos ambientes midiáticos modernos, que permitem diferentes tipos e ritmos de exibição, alterando, por exemplo, a experiência da sala de cinema.

10 John Cage também bebeu da fonte mallarmaica para construir a sua própria escola de escrita não intencional. Segundo Liz Kotz (2007: 100), a partir do diálogo com Cage, emergiram na poesia dos anos 1950 e 1960 diferentes tipos de prática: tanto aquelas que trabalhavam com justaposições e sobreposições de materiais pré-existentes (como os trabalhos de Jackson Mac Low e John Ashbery) como um modelo de instruções curtas, que propunham ações, experiências, processos, usando para isso uma linguagem coloquial e por vezes instrumental, como o Fluxus.

\section{No original,}

Prenez un journal. / Prenez des ciseaux. / Choisissez dans ce journal un article ayant la longueur que vous comptez donner à votre poème. / Découpez l'article. / Découpez ensuite avec soin chacun des mots qui forment cet article et mettez-les dans un sac. / Agitez doucement. / Sortez ensuite chaque coupure l'une après l'autre. / Copiez les consciencieusement dans l'ordre où elles ont quitté le sac. / Le poème vous ressemblera. / Et vous voilà un écrivain infiniment original et d'une sensibilité charmante, encore qu'incomprise du vulgaire.

N. 41 - 12/ 2019 | 291-315 - ISSN 2183-2242 | http:/dx.doi.org/10.21747/21832242/litcomp41a13 
Disponível em <http://web.sonoma.edu/users/r/renaudin/fr202/files/202P22.pdf >. Último acesso em $22 \mathrm{de}$ julho de 2019. Tradução minha.

12 Conhecidos como The Nova Trilogy ou The Cut-up Trilogy.

13 Migliorin (2005) se refere a um filme-dispositivo contemporâneo que teria parentesco com o cinemaverdade dos anos 1960, mas que, à diferença deste, traria personagens conscientes do papel que exercem diante das câmeras.

14 No caso de Coutinho, tratava-se de um fato inédito na trajetória do diretor, reconhecido pela intensa investigação prévia realizada por sua equipe antes do momento das filmagens. Mas, diferentemente do que norteou Acidente, neste caso a escolha da cidade que protagonizaria a obra se deu por conveniência: o pequeno município de São João do Rio do Peixe seria o único na região a oferecer um "bom hotel". De toda forma, o dispositivo de Coutinho se configurava como exceção em meio ao conjunto de sua obra, e não uma prática corrente, como no trabalho de Cao Guimarães.

15 No original, "El cine es un medio para hacer descubrir la poesía, sea la poesía de un poeta, sea la poesía del mundo. Pero no es el cine lo que es poético, es la cosa mostrada lo que lo es". Tradução minha.

16 Com isso, a construção de uma gramática própria do cinema, considerada por ele arbitrária naquele momento, consistia na criação de um estilo, o que, segundo o próprio, estaria relacionado ao uso da "subjetiva indireta livre". Para Pasolini (1970: 25-6), a "subjetiva indireta livre" seria o equivalente à narração indireta livre na literatura. Como o cinema não teria possibilidades de interiorização e abstração da palavra, jamais seria possível haver uma correspondência perfeita.

17 Refiro-me ao termo cunhado por Barthes no artigo "Escritores/escreventes" (1960). Para Barthes, os escreventes surgiram a partir da Revolução Francesa, apropriando-se da linguagem com fins políticos. Enquanto o escritor seria norteado por questões relativas, por exemplo, a estilo, composição, paciência e correção, o escrevente trabalharia a palavra sem ambiguidade e, portanto, mais relacionada ao seu aspecto de comunicar. De toda forma, Barthes (2003) reconhece que todos nos movemos entre os dois postulados, combinando características de escritores e escreventes para gerar "bastardos" com diferentes gradações e funções complementares.

N. 41 - 12/ 2019 | 291-315 - ISSN 2183-2242 | http:/dx.doi.org/10.21747/21832242/litcomp41a13 


\section{Bibliografia}

Almeida, Rafael de (2016), "Cao Guimarães: por uma escrita que se faz enquanto se pensa", Revista da Associação Nacional dos Programas de Pós-Graduação em Comunicação / Ecompós, Brasília, v. 19, n. 1.

-- (2017), "A cidade como acontecimento ou a propósito de Acidente", Sessões do Imaginário, v. 22, n. 37, PUC-RS, 86-93.

Assunção, Teodoro Rennó (2001), “Cinema (quase) sem literatura - Nota sobre os 'curtas experimentais'", Aletria: revista de estudos de literatura, v. 8, UFMG, 116-123.

Barthes, Roland (2003), Ensayos críticos, Buenos Aires, Seix Barral.

Cohn, Sergio / Ferron, Fabio Maleronka / Herencia, José Luiz et alii (2010), Produção cultural, v. 3, Rio de Janeiro, Beco do Azougue.

Diógenes, Paulo César Rodrigues, "Sobre máquinas de escrita e remistura: o método cut-up de William Burroughs", Línguas \& Letras, v. 13, n. 25, Unioeste, 343-370.

Guimarães, Cao (2004), "Concerto para clorofila (descrição da obra)", $<$ http://www.caoguimaraes.com/obra/concerto-para-clorofila/> (último acesso em 25/06/2019).

-- (2015), "Minas é onde o mistério se escondeu - entrevista concedida a Juliana Afonso e Cézar Félix", Revista Sagarana, n. 49, <http://revistasagarana.com.br/entrevista-caoguimaraes/> (último acesso em 02/07/2019).

Kotz, Liz (2007), Words to Be Looked At: Language in 1960s Art, Cambridge (MA), MIT Press.

Lins, Consuelo (2007), “Tempo e dispositivo no documentário de Cao Guimarães”, Devires cinema e humanidades, v. 4, UFMG, 118-127.

Lobato, Pablo, "Arte da infinita singularidade - entrevista concedida a Daniel Oliveira", Jornal O Tempo, 28 ago. 2016, <https://www.otempo.com.br/diversao/magazine/arte-da- 
infinita-singularidade-1.1362377> (último acesso em 09/12/2019).

Martins, Júlio (2012), "Pablo Lobato: por um mínimo de vida em estado bruto”, in: Brasil, André e Teia (orgs.), Teia 2002-2012, Belo Horizonte, Teia, 156-168.

Migliorin, Cesar (2005), “O dispositivo como estratégia narrativa”, <http://www.estacio.br/graduacao/cinema/digitagrama/numero3/cmigliorin.as> (último acesso em 02/07/2019).

Nancy, Jean-Luc (2013), “Fazer, a poesia”, Alea, vol. 15/2, UFRJ, 414-422.

Parente, André (2007), "Cinema em trânsito: do dispositivo do cinema ao cinema do dispositivo", in: Penafria, Manuela / Martins, India Mara (orgs.), Estéticas do digital: cinema e tecnologia, Covilhã, Labcom, 3-31.

Pasolini, Pier Paolo (1970), “Cine de poesía”, in: Pasolini, Pier Paolo / Rohmer, Eric (1970), Cine de poesía contra cine de prosa, Barcelona, Anagrama, 9-41.

Remes, Justin (2015), “Boundless Ontologies: Michael Snow, Wittgenstein, and the Textual Film", Cinema Journal, Volume 54, Number 3, Spring, 69-87.

Valente, Eduardo (2006), "Percurso de Acidente", Revista Cinética, <http://www.revistacinetica.com.br/acidentepercurso.htm> (último acesso em 02/07/2019).

Wall-Romana, Christophe (2013), Cinepoetry - Imaginary Cinemas in French Poetry, Nova York, Fordham University.

\section{Filmografia}

Coutinho, Eduardo (2005), o fim e o princípio, DVD, 35mm, $110 \mathrm{~min}$.

Duchamp, Marcel (1926), Anemic Cinéma, 35mm, 6 min, <https://www.youtube.com/watch?v=dXINTf8kXCc> (último acesso em 02/07/2019). 
Griffith, D.W. (1916), Intolerance, 35mm, $182 \mathrm{~min},<$ https://www.youtube.com/watch?v=zzXYPJAGkg> (último acesso em 02/07/2019).

Guimarães, Cao (2002), Rua de Mão Dupla, DV, 75 min, <https://vimeo.com/137889393> (último acesso em 02/07/2019).

-- (2010), Ex-Isto, HDV, $86 \mathrm{~min},<$ https://vimeo.com/132978964> (último acesso em 02/07/2019).

-- / Lobato, Pablo (2006), Acidente, Super 8/mini DV, 72 min, <https://vimeo.com/137519082> (último acesso em 02/07/2019).

-- / Neuenschwander, Rivane (2001), Word World, Super 8, 8 min.

Léger, Fernand; Murphy, Dudley (1924), Ballét Mecanique, 35mm, 12 min, <https://www.youtube.com/watch?v=ZTdlnE4Vy2c> (último acesso em 02/07/2019).

Lobato, Pablo (2000), Cerrar a porta, vídeo, 4 min 45.

-- (2007), Outono, 35mm, $21 \mathrm{~min}$.

-- (2010), Queda, HD, 14 min 35.

-- (2011), Bronze revirado, videoinstalação, 4 min 52, loop.

-- (2013), Ventos de Valls, digital, $88 \mathrm{~min}$.

-- (2014), Corda, vídeo, 7 min 15, loop.

Sheeler, Charles; Strand, Paul (1921), Manhatta, 35mm, 9 min, <https://www.youtube.com/watch?v=kuuZS2phD10> (último acesso em 02/07/2019).

Snow, Michael (1982), So Is This, 16mm, 48 min, <https://www.youtube.com/watch?v=J48XKZ18qtU> (último acesso em 02/07/2019). 
Ana Gabriela Dickstein Roiffe é doutora em Letras pela Pontifícia Universidade Católica do Rio de Janeiro (PUC-Rio), com estágio de doutorado na Universidade de Princeton, EUA (bolsa da Fulbright e da Capes). Participou de congressos nacionais e internacionais, apresentando resultados de pesquisas sobre diferentes relações entre texto e imagem, a partir do cinema, da literatura e da arte contemporânea. Atualmente é Professora Substituta do Departamento de Estudos Culturais e Mídia na Universidade Federal Fluminense (UFF). 